\title{
Rheumatoid Arthritis and Primary Biliary Cirrhosis: Cause, Consequence, or Coincidence?
}

\author{
Daniel S. Smyk, ${ }^{1}$ Dimitrios P. Bogdanos, ${ }^{1,2}$ Maria G. Mytilinaiou, ${ }^{1,2}$ \\ Andrew K. Burroughs, ${ }^{3}$ and Eirini I. Rigopoulou ${ }^{2}$ \\ ${ }^{1}$ Institute of Liver Studies, Division of Transplantation Immunology and Mucosal Biology, School of Medicine, \\ King's College London, London SE5 9RS, UK \\ ${ }^{2}$ Department of Medicine, University Hospital of Larissa, University of Thessaly Medical School, Viopolis, \\ 41110 Larissa, Greece \\ ${ }^{3}$ The Sheila Sherlock Liver Centre and University Department of Surgery, Royal Free Hospital, \\ London NW32QG, UK
}

Correspondence should be addressed to Dimitrios P. Bogdanos, dimitrios.bogdanos@kcl.ac.uk

Received 28 July 2012; Accepted 28 September 2012

Academic Editor: Pierre Youinou

Copyright () 2012 Daniel S. Smyk et al. This is an open access article distributed under the Creative Commons Attribution License, which permits unrestricted use, distribution, and reproduction in any medium, provided the original work is properly cited.

\begin{abstract}
Primary biliary cirrhosis (PBC) is a progressive cholestatic liver disease characterized serologically by cholestasis and the presence of high-titre antimitochondrial antibodies and histologically by chronic nonsuppurative cholangitis and granulomata. PBC patients often have concomitant autoimmune diseases, including arthropathies. This raises the question as to whether there are shared features in the pathogenesis of those diseases with the pathogenesis of PBC. Epidemiological and large case studies have indicated that although the incidence of rheumatoid arthritis (RA) is not significantly raised in PBC patients, there appears to be a higher rate of RA in PBC patients and their relatives. Genetic studies have demonstrated that several genes implicated in PBC have also been implicated in RA. Epigenetic studies provided a wealth of data regarding RA, but the findings on epigenetic changes in PBC are very limited. As well, certain infectious agents identified in the pathogenesis of PBC may also play a role in the pathogenesis of RA. These data suggest that although RA is not significantly present in PBC, some individuals with certain genetic traits and environmental exposures may develop both conditions. This concept may also apply to other concomitant diseases found in PBC patients.
\end{abstract}

\section{Introduction}

Primary biliary cirrhosis (PBC) is a chronic cholestatic, autoimmune liver disease characterised by progressive inflammatory destruction of the intrahepatic bile ducts, with fibrosis leading to cirrhosis $[1-5]$ and liver failure $[6,7]$. The disease most commonly affects middle-aged females [8-10]. $\mathrm{PBC}$ is often found to affect more than one member of the same family, and it appears that first degree relatives (FDRs) of $\mathrm{PBC}$ patients have and increased risk of developing the disease [1-5]. There is a consensus that the incidence and prevalence of PBC is increasing [11-15]. This may be due to a true increase in the disease or due to the awareness for the disease amongst clinicians and the meticulous diagnostic assessment, such as disease-specific autoantibody testing.
$\mathrm{PBC}$ is characterised by several disease-specific autoantibody profiles [16], which are a key component of the diagnostic workup. Included in the autoantibody profiles are antimitochondrial antibodies (AMA) $[17,18]$ and/or disease-specific antinuclear antibody (ANA) $[19,20]$. AMA positivity appears to be indicative of future PBC development [21]. Autoimmune rheumatic diseases such as Sjögren's syndrome and systemic sclerosis, as well as other extrahepatic autoimmune manifestations such as autoimmune thyroiditis, are frequently found to be concomitant with PBC $[2,22,23]$. PBC generally progresses slowly, although the clinical course in some cases may advance in a fast pace $[6,24]$.

The diagnostic criteria of PBC include (1) biochemical evidence of cholestasis such as elevated alkaline phosphatase (ALP) and $\gamma \mathrm{GT}$, (2) presence of disease-specific 
antimitochondrial antibodies, and (3) histological features of PBC [2]. Currently, two of the three criteria are needed for PBC diagnosis $[2,4]$. Additionally, it is common to see elevated levels of immunoglobulin $\mathrm{M}(\operatorname{IgM})[2,4,25]$.

PBC-specific AMA predominantly targets the E2 subunits of the oxoacid dehydrogenase complexes (OADCs), and especially that of the pyruvate dehydrogenase complex (PDC-E2) [18, 21, 26]. Approximately 3-10\% of patients with PBC are negative for these autoantibodies [21, 2730]. Although these autoantibodies may be found in other conditions, anti-PDC-E2-specific AMA are rarely found in other conditions $[31,32]$. AMA seropositivity in patients with autoimmune rheumatic diseases indicates the presence of PBC or the future development of the disease [33]. Prospective studies have demonstrated that the presence of AMA predicts the future development of PBC in asymptomatic, cholestatic, or acholestatic individuals [17, 34]. Approximately $50 \%$ of patients have disease-specific ANA [35-37]. Although AMA does not appear to have prognostic significance, it has been suggested that PBC-specific ANA reactivities may have prognostic significance, although larger studies are needed to substantiate the clinical relevance of these autoantibodies [20, 37-39]. Other autoantibody profiles have also been reported in patients with PBC but their pathogenic relevance and diagnostic utility remain unclear [40-42].

Both genetic and environmental triggers have been considered important for the induction of PBC, as well as other autoimmune diseases $[43,44]$. Environmental triggers include infectious and noninfectious agents [22, 45-47]. Impairment in the immunosuppressory functions of the host appears to be a feature of PBC $[48,49]$.

As many patients with $\mathrm{PBC}$ also demonstrate concomitant rheumatic conditions, this paper will examine the epidemiological and genetic data surrounding rheumatoid arthritis (RA) and PBC, using larger cohort studies and epidemiological studies, as well as genetic investigations. These data may indicate that the presence of RA with PBC and vice versa may be due to a causal link, as opposed to a casual observation. A possible link with common infectious triggers will also be introduced. This paper is not intended as a literature review of RA in $\mathrm{PBC}$, but rather as an examination of the presence of the two conditions in one another, as well as common genetic traits that may infer susceptibility to both. These commonalities, and the coexistence of the two conditions in one individual, may contribute to the development of what is known as the Kaleidoscope of autoimmunity [50-57]. This Kaleidoscope highlights the fact that many patients with one autoimmune condition also have other concomitant autoimmune conditions and that patients with one autoimmune disease are at risk of developing another $[51,57]$.

\section{Rheumatoid Arthritis in Primary Biliary Cirrhosis and Vice Versa}

Several musculoskeletal conditions are known to affect PBC patients, including hypertrophic osteoarthropathy, osteo- porosis, avascular necrosis, medullary bone defects due to cholesterol deposition, and RA [58]. However, it is unclear how many cases fit the diagnostic criteria for RA [58-62]. An early study by Sherlock and Scheuer [63] notes that $5 \%$ of a cohort of 100 PBC patients had concomitant RA, with approximately $50 \%$ of $\mathrm{PBC}$ patients being positive for rheumatoid factor (RF). A study by Siegel and colleagues [58] identified 25 patients who did fit the diagnostic criterion for both RA and PBC. Elevated transaminases, ALP, and bilirubin were observed in the cohort, and 13 patients were in PBC stages 1 or 2 [58]. That study found that RA was diagnosed before PBC in 17 cases (mean 11.8 years prior) [58]. In the remaining cases, RA was diagnosed after $\mathrm{PBC}$, with a mean diagnosis at 5 years after $\mathrm{PBC}$, although this ranged from 2 to 14 years [58]. Those researchers suggested that AMA testing should be performed in RA patients who display abnormal LFTs [58]. Caramella et al. [64] report two cases of RA and PBC with Sjögren's ruled out, where one patient developed PBC before RA and the other developed RA before PBC. That study estimated the prevalence of RA in $\mathrm{PBC}$ to be between 1.8 and $5.6 \%$, based on other reports [64-66], but it is unknown whether earlier studies based their RA diagnoses on the American College of Rheumatology (ACR) diagnostic protocols. Marasini and colleagues [66] screened 170 patients with histologically confirmed PBC for connective tissue diseases and Raynaud's phenomenon. Connective tissue disease was found in 47 patients, with 21 having systemic sclerosis, 34 being ANA positive, 33 being ACA positive, and 27 patients having extractable nuclear antigen [66]. Three patients had RA, which was diagnosed using ACR criteria [66].

Several other studies have reported the presence of PBCrelated features in patients with RA PBC but a clear definition of the hierarchy of events leading to the development of abnormal liver biochemistry with or without features of overt liver disease related to PBC is lacking. Generally, liver disease is not seen as a significant feature of RA, although $18-50 \%$ of RA patients have abnormal LFTs [67]. As well, several studies have noted liver pathology in RA patients, and others have examined the presence of PBC in RA patients. One retrospective autopsy series of RA patients prior to methotrexate use found that $65 \%$ of 182 RA cases with liver biopsies had evident liver pathology [68]. This included chronic mild inflammatory infiltrates of portal tracts and small foci of necrosis, as well as steatosis [68]. However, it is not known whether any of those patients had diagnosed PBC. Another study notes that AMA positivity in RA at $18 \%$ [69]. This is of interest given the predictive value of AMA for $\mathrm{PBC}$, although the specificity of the AMA in RA patients is unclear.

The above studies indicate that RA is present in some PBC patients and vice versa, but larger prospective studies are needed to determine whether there is a significant and undisputed evidence of the presence of one disease in the other. As well, genetic studies may also shed light on the predisposition of some individuals to develop both conditions. 


\section{The Link of PBC with RA: Is There Any Evidence from Epidemiological Studies?}

Several epidemiological studies have been conducted to investigate risk factors for the development of $\mathrm{PBC}[70$ 73]. These studies have largely been based on questionnaires that investigate geographical and lifestyle data, in addition to personal and familial medical and surgical histories. A study by Parikh-Patel and colleagues [72] administered a standardized US national Health and Nutrition Examination Study (NHANES) questionnaire to $241 \mathrm{PBC}$ patients from the USA, in addition to 261 of their siblings and 141 friends as controls. No mention was made as to the incidence of RA in the PBC cohort [72]. Another study conducted by Gershwin et al. [71] also utilised a NHANES style questionnaire. The cohort in that study consisted of 1032 PBC patients from 23 tertiary care centres in the USA, 1041 controls selected from a random-digit-dialling protocol, which were sex, age, race and geographically matched. In the medical histories, it was found that $10 \%$ of $\mathrm{PBC}$ cases also had RA, although $8 \%$ of controls also reported RA [71]. RA was reported in $26 \%$ of first degree relatives (FDRs) of PBC patients, compared to $22 \%$ of control relatives [71]. Interestingly, among the FDR, females reported a higher incidence of RA than the male relatives. Mothers of $\mathrm{PBC}$ patients were the most affected (13.8\%) followed by sisters (11\%) [71]. Prince et al. [73] conducted an epidemiological study involving 318 patients from a geographically defined epidemiological study and 2258 from a PBC support group, in addition to 2438 controls. The odds ratio for RA in the epidemiological group was 1.52 compared to 1.21 in the support group [73]. Corpechot and colleagues [70] administered a standardized questionnaire to $222 \mathrm{PBC}$ patients and 509 age, sex, and residentially matched controls [70]. RA was found in 3\% of cases and $1 \%$ of controls, which was not found to be statistically significant [70]. As well, $2 \%$ of FDR of PBC cases, and $1 \%$ of FDR of controls also reported RA, and this was also not found to be statistically significant [70]. Epidemiologically, it does not appear that RA is significantly increased in PBC patients. However, the rates of RA were higher in PBC cohorts as well as female FDR, which may suggest a common background for both conditions in some cases.

\section{Genetic Studies in PBC and RA: The Missing Link?}

Genetic and genome-wide association studies (GWAS) have recently shed light on the genetic background of $\mathrm{PBC}$ and RA. Genes implicated in PBC lay within both HLA and non-HLA regions (Table 1) [74-81]. Genetic and GWA studies have also been performed in RA, and multiple susceptibility loci have been identified, also within HLA and non-HLA regions [82-87]. Interestingly, several common genes have been identified in RA and PBC (Table 1), although a vast majority of implicated genes in both diseases do not overlap. Overlapping genes include HLA-DQB1, STAT4, IRF5, MMEL1, CTLA4, and possibly CXCR5. It may be the
TABLE 1: Major susceptibility genes associated with primary biliary cirrhosis (PBC), as reported through genome-wide association studies. Note that several positive associations are shared between $\mathrm{PBC}$ and rheumatoid arthritis (RA).

\begin{tabular}{lcc}
\hline Gene & PBC & RA \\
\hline HLA & + & - \\
DR8 & + & + \\
DQB1 & + & - \\
DRB1 & + & - \\
DQA1 & + & - \\
DQA2 & & \\
Non-HLA & + & + \\
STAT4 & + & - \\
SPIB & + & + \\
IRF5 & + & - \\
IL12A & + & - \\
IL12RB & + & + \\
MMEL1 & + & $?$ \\
CXCR5 & + & - \\
NFKB1 & + & + \\
CTLA4 & + & \\
\hline
\end{tabular}

?: question mark indicates that there are no conclusive data regarding the role of CCXR5 as a risk factor in RA, with some reports providing data in support and other against.

case that individuals with a common genetic profile may be more susceptible to developing concomitant RA and PBC, or $\mathrm{PBC}$ in RA. On the other hand, some individuals with other genetic characteristics for $\mathrm{RA}$ or $\mathrm{PBC}$, in which genes do not overlap, will not be susceptible to developing particular concomitant autoimmune disease. This is likely the scenario in the majority of patients, as the epidemiological data does not suggest a large proportion of RA patients with $\mathrm{PBC}$ and vice versa.

\section{Epigenetic Studies in RA and PBC}

An increasing body of evidence accumulated in recent years suggesting that epigenetic changes such as histone modifications and DNA methylation can manipulate immune reactions and participate to the development of autoaggression [88, 89]. Epigenomic modifications have been demonstrated in systemic lupus erythematosus, Sjögren's syndrome, multiple sclerosis, inflammatory bowel diseases, and several other autoimmune diseases [88, 89]. While the role of epigenetic changes involved in the pathogenesis of RA has been extensively studied, data on the involvement of epigenetics in the induction of PBC are scarce $[90,91]$. Evidence of enhanced histone acetylation at promoters of genes pathogenetically-related to RA has been provided $[92,93]$. As well, various inhibitors of histone deacetylases have shown promising results in experimental models of RA [94, 95]. Histone deacetylases are the group of enzymes that remove acetyl groups from histone tails, the removal of which condensation of chromatin structures and repression of gene expression [91]. In addition, data obtained by 
independent groups of investigators have reported evidence of disturbed patterns of DNA methylation in RA [91]. A meticulous analysis of epigenetic changes in RA synovial fibroblasts (RASFs) is underway, and it is anticipated that in the years to come we will delineate the behaviour of RASFs and the exact time frame that the epigenetic changes in RASFs are induced [91]. RASFs respond to proinflammatory cytokines such as interleukin- $1 \beta$ and tumor necrosis factor$\alpha$ and can drive joint inflammation [91]. Intriguing new data have demonstrated that RASFs can migrate via the bloodstream to implanted cartilage at a distant site; such a migratory potential may explain the polyarticular involvement characteristic of RA [96].

In contrast to the wealth of data in RA, epigenetic studies in PBC have been largely studied by one group and the data are limited [90]. Mitchell et al. [90] have tested the hypothesis that $\mathrm{X}$-linked promoters of variable $\mathrm{X}$ chromosome inactivation (XCI) genes are dysregulated in $\mathrm{PBC}$ through aberrations in promoter methylation. They have based their hypothesis on previous observations indicating that women with $\mathrm{PBC}$ are characterized by an enhanced rate of preferential $\mathrm{X}$ monosomy, with random XCI in peripheral blood lymphocytes isolated from women with PBC compared to demographically matched women [97]. These investigators have tested their hypothesis in discordant monozygotic twin $\mathrm{PBC}$ pairs and found that two genes, CLIC2 and PIN4, exhibited decreased transcription in 3 out of 4 affected pairs compared to unaffected healthy twins in discordant twin pairs [90]. Of relevance, Chabchoub et al. analyzed XCI profiles of females RA patients and found skewed XCI in $34.2 \%$ of them compared to $11 \%$ found in the control population [98].

\section{An Infectious Agent Linking PBC and RA}

Assuming that a common genetic link exists between some $\mathrm{RA} / \mathrm{PBC}$ patients, it may also be the case that common infectious triggers may also be involved in the induction of both diseases in particular individuals. One of the most widely studied infectious triggers of PBC is Escherichia coli (E. coli), due to the high incidence of recurrent urinary tract infections (rUTI) in PBC patients and the fact that E. coli is the most commonly isolated bacteria in rUTI [47]. Molecular mimicry and cross-reactivity between selfand bacterial antigens are believed to play a role in the induction of PBC [99]. Several infections have also been linked to RA, most notably Epstein-Barr's virus, parvovirus B19, chronic hepatitis C virus, Proteus mirabilis, Klebsiella pneumoniae, and E. coli $[100,101]$. Of interest, anti-E. coli IgM has been found to be elevated in RF-positive RA patients [102]. A recent study by Newkirk and colleagues [100] examined the antibacterial antibody levels in patients with RF-positive and negative inflammatory arthritis. Bacteria were isolated from stool and urine samples, with IgM and IgA antibacterial, and RF antibodies being assessed by ELISA. Increased colonization of Group D E. coli was found in RF-positive patients, and increased colonization of Group B2 E. coli was found in RF-negative patients [100]. RF- negative patients were noted to have a less severe disease phenotype, but had higher levels of IgA anti-E. coli [100]. Those investigators suggest a possible role for E. coli in the early pathogenesis of RA [100]. Whether or not E. coli plays a significant role in the pathogenesis of RA warrants further investigation. It would be of interest to investigate the incidence of rUTI in PBC patients with RA, as E. coli infection compounded with a particular genetic trait may be the missing link between RA in PBC.

\section{Conclusion}

Concomitant arthritides are observed in patients with PBC, which raises the possibility of a common aetiology between $\mathrm{PBC}$ and RA. Indeed, RA is observed in PBC patients and vice versa, although not at a significantly increased level. Although epidemiological data of RA in PBC do not suggest a significantly increased incidence of RA in PBC, $\mathrm{RA}$ does appear to be a feature in a small number of PBC patients and their relatives. Recent genetic studies have identified several common disease-associated genes between the two conditions, which may infer a susceptibility to both diseases in a minority of patients. Epigenetic modifications are well studied in RA, and such investigations are also needed in PBC. The role of infectious triggers, and especially those responsible for recurrent or complicated urinary tract infections, may serve as a trigger of both conditions, and this warrants further investigation.

\section{Abbreviations}

$\begin{array}{ll}\text { AMA: } & \text { Antimitochondrial antibodies } \\ \text { ANA: } & \text { Antinuclear antibodies } \\ \text { E. coli: } & \text { Escherichia coli } \\ \text { FDR: } & \text { First degree relative } \\ \text { GWAS: } & \text { Genome-wide association study } \\ \text { PBC: } & \text { Primary biliary cirrhosis } \\ \text { PDC-E2: } & \text { Pyruvate dehydrogenase complex E2 subunit } \\ \text { RA: } & \text { Rheumatoid arthritis } \\ \text { RF: } & \text { Rheumatoid factor } \\ \text { RASF: } & \text { RA synovial fibroblasts } \\ \text { rUTI: } & \text { Recurrent urinary tract infection } \\ \text { XCI: } & \text { X chromosome inactivation. }\end{array}$

\section{References}

[1] S. Hohenester, R. P. J. Oude-Elferink, and U. Beuers, "Primary biliary cirrhosis," Seminars in Immunopathology, vol. 31, no. 3, pp. 283-307, 2009.

[2] M. M. Kaplan and M. E. Gershwin, "Primary biliary cirrhosis," The New England Journal of Medicine, vol. 353, no. 12, pp. 1261-1273, 2005.

[3] T. Kumagi and E. J. Heathcote, "Primary biliary cirrhosis," Orphanet Journal of Rare Diseases, vol. 3, no. 1, article 1, 2008.

[4] K. D. Lindor, M. E. Gershwin, R. Poupon, M. Kaplan, N. V. Bergasa, and E. J. Heathcote, "Primary biliary cirrhosis," Hepatology, vol. 50, no. 1, pp. 291-308, 2009.

[5] J. Neuberger, "Primary biliary cirrhosis," The Lancet, vol. 350, no. 9081, pp. 875-879, 1997. 
[6] E. J. Heathcote, "Management of primary biliary cirrhosis," Hepatology, vol. 31, no. 4, pp. 1005-1013, 2000.

[7] R. Poupon, "Primary biliary cirrhosis: a 2010 update," Journal of Hepatology, vol. 52, no. 5, pp. 745-758, 2010.

[8] C. A. Aoki, C. M. Roifman, Z. X. Lian et al., "IL-2 receptor alpha deficiency and features of primary biliary cirrhosis," Journal of Autoimmunity, vol. 27, no. 1, pp. 50-53, 2006.

[9] Y. Dahlan, L. Smith, D. Simmonds et al., "Pediatric-onset primary biliary cirrhosis," Gastroenterology, vol. 125, no. 5, pp. 1476-1479, 2003.

[10] P. Invernizzi, M. G. Alessio, D. S. Smyk et al., "Autoimmune hepatitis type 2 associated with an unexpected and transient presence of primary biliary cirrhosis-specific antimitochondrial antibodies: a case study and review of the literature," BMC Gastroenterology, vol. 12, article 92, 2012.

[11] K. Boonstra, U. Beuers, and C. Y. Ponsioen, "Epidemiology of primary sclerosing cholangitis and primary biliary cirrhosis: a systematic review," Journal of Hepatology, vol. 56, no. 5, pp. 1181-1188, 2012.

[12] O. E. W. James, R. Bhopal, D. Howel, J. Gray, A. D. Burt, and J. V. Metcalf, "Primary biliary cirrhosis once rare, now common in the United Kingdom?" Hepatology, vol. 30, no. 2, pp. 390-394, 1999.

[13] W. R. Kim, K. D. Lindor, G. R. Locke et al., "Epidemiology and natural history of primary biliary cirrhosis in a U.S. community," Gastroenterology, vol. 119, no. 6, pp. 16311636, 2000.

[14] C. Selmi, P. Invernizzi, E. B. Keefe et al., "Epidemiology and pathogenesis of primary biliary cirrhosis," Journal of Clinical Gastroenterology, vol. 38, no. 3, pp. 264-271, 2004.

[15] S. Sood, P. J. Gow, J. M. Christie, and P. W. Angus, "Epidemiology of primary biliary cirrhosis in Victoria, Australia: high prevalence in migrant populations," Gastroenterology, vol. 127, no. 2, pp. 470-475, 2004.

[16] D. P. Bogdanos, G. Mieli-Vergani, and D. Vergani, "Autoantibodies and their antigens in autoimmune hepatitis," Seminars in Liver Disease, vol. 29, no. 3, pp. 241-253, 2009.

[17] D. P. Bogdanos and L. Komorowski, "Disease-specific autoantibodies in primary biliary cirrhosis," Clinica Chimica Acta, vol. 412, no. 7-8, pp. 502-512, 2011.

[18] P. S. C. Leung, R. L. Coppel, A. Ansari, S. Munoz, and M. E. Gershwin, "Antimitochondrial antibodies in primary biliary cirrhosis," Seminars in Liver Disease, vol. 17, no. 1, pp. 61-69, 1997.

[19] D. P. Bogdanos, A. Pares, J. Rodés et al., "Primary biliary cirrhosis specific antinuclear antibodies in patients from Spain," American Journal of Gastroenterology, vol. 99, no. 4, pp. 763-765, 2004.

[20] P. Invernizzi, M. Podda, P. M. Battezzati et al., "Autoantibodies against nuclear pore complexes are associated with more active and severe liver disease in primary biliary cirrhosis," Journal of Hepatology, vol. 34, no. 3, pp. 366-372, 2001.

[21] L. Muratori, A. Granito, P. Muratori, G. Pappas, and F. B. Bianchi, "Antimitochondrial antibodies and other antibodies in primary biliary cirrhosis: diagnostic and prognostic value," Clinics in Liver Disease, vol. 12, no. 2, pp. 261-276, 2008.

[22] D. P. Bogdanos, C. Rigamonti, and D. Smyk, "Mytilinaiou MG, Rigopoulou EI, Burroughs AK," in Systemic SclerosisAn Update on the Aberrant Immune System and Clinical Features, T. Radstake, Ed., pp. 151-166, Intech, Rijeka, Croatia, 2012.

[23] C. Rigamonti, D. P. Bogdanos, M. G. Mytilinaiou et al., "Primary biliary cirrhosis associated with systemic sclerosis: diagnostic and clinical challenges," International Journal of Rheumatology, vol. 2011, Article ID 976427, 2011.

[24] T. Kumagi and M. Onji, "Presentation and diagnosis of primary biliary cirrhosis in the 21st century," Clinics in Liver Disease, vol. 12, no. 2, pp. 243-259, 2008.

[25] C. Duarte-Rey, D. P. Bogdanos, P. S. Leung, J. M. Anaya, and M. E. Gershwin, "IgM predominance in autoimmune disease: genetics and gender," Autoimmunity Reviews, vol. 11, no. 6-7, pp. A404-A412, 2012.

[26] E. I. Rigopoulou, E. T. Davies, D. P. Bogdanos et al., "Antimitochondrial antibodies of immunoglobulin G3 subclass are associated with a more severe disease course in primary biliary cirrhosis," Liver International, vol. 27, no. 9, pp. 12261231, 2007.

[27] N. Bizzaro, G. Covini, F. Rosina et al., "Overcoming a "probable" diagnosis in antimitochondrial antibody negative primary biliary cirrhosis: study of 100 sera and review of the literature," Clinical Reviews in Allergy and Immunology, vol. 42, no. 3, pp. 288-297, 2012.

[28] C. Dähnrich, A. Pares, L. Caballeria et al., "New ELISA for detecting primary biliary cirrhosis-specific antimitochondrial antibodies," Clinical Chemistry, vol. 55, no. 5, pp. 978985, 2009.

[29] P. Invernizzi, A. Crosignani, P. M. Battezzati et al., "Comparison of the clinical features and clinical course of antimitochondrial antibody-positive and -negative primary biliary cirrhosis," Hepatology, vol. 25, no. 5, pp. 1090-1095, 1997.

[30] E. I. Rigopoulou, D. P. Bogdanos, C. Liaskos et al., "Antimitochondrial antibody immunofluorescent titres correlate with the number and intensity of immunoblot-detected mitochondrial bands in patients with primary biliary cirrhosis," Clinica Chimica Acta, vol. 380, no. 1-2, pp. 118-121, 2007.

[31] W. Bernal, F. Meda, Y. Ma, D. P. Bogdanos, and D. Vergani, "Disease-specific autoantibodies in patients with acute liver failure: the King's College London experience," Hepatology, vol. 47, no. 3, pp. 1096-1097, 2008.

[32] P. S. C. Leung, L. Rossaro, P. A. Davis et al., "Antimitochondrial antibodies in acute liver failure: implications for primary biliary cirrhosis," Hepatology, vol. 46, no. 5, pp. 1436-1442, 2007.

[33] C. Liaskos, D. P. Bogdanos, E. I. Rigopoulou, and G. N. Dalekos, "Development of antimitochondrial antibodies in patients with autoimmune hepatitis: art of facts or an artifact?" Journal of Gastroenterology and Hepatology, vol. 22, no. 3, pp. 454-455, 2007.

[34] J. V. Metcalf, H. C. Mitchison, J. M. Palmer, D. E. Jones, M. F. Bassendine, and O. F. W. James, "Natural history of early primary biliary cirrhosis," The Lancet, vol. 348, no. 9039, pp. 1399-1402, 1996.

[35] C. Duarte-Rey, D. Bogdanos, C. Y. Yang et al., "Primary biliary cirrhosis and the nuclear pore complex," Autoimmunity Reviews, vol. 11, no. 12, pp. 898-902, 2012.

[36] S. Itoh, T. Ichida, T. Yoshida et al., "Autoantibodies against a $210 \mathrm{kDa}$ glycoprotein of the nuclear pore complex as a prognostic marker in patients with primary biliary cirrhosis," Journal of Gastroenterology and Hepatology, vol. 13, no. 3, pp. 257-265, 1998.

[37] J. Wesierska-Gadek, H. Hohenauer, E. Hitchman, and E. Penner, "Autoantibodies from patients with primary biliary cirrhosis preferentially react with the amino-terminal domain of nuclear pore complex glycoprotein gp210," Journal of Experimental Medicine, vol. 182, no. 4, pp. 1159-1162, 1995. 
[38] M. G. Mytilinaiou, W. Meyer, T. Scheper et al., "Diagnostic and clinical utility of antibodies against the nuclear body promyelocytic leukaemia and Sp100 antigens in patients with primary biliary cirrhosis," Clinica Chimica Acta, vol. 413, no. 15-16, pp. 1211-1216, 2012.

[39] E. I. Rigopoulou, E. T. Davies, A. Pares et al., "Prevalence and clinical significance of isotype specific antinuclear antibodies in primary biliary cirrhosis," Gut, vol. 54, no. 4, pp. 528-532, 2005.

[40] S. Gabeta, G. L. Norman, N. Gatselis et al., "IgA anti-b2GPI antibodies in patients with autoimmune liver diseases," Journal of Clinical Immunology, vol. 28, no. 5, pp. 501-511, 2008.

[41] C. Liaskos, G. L. Norman, A. Moulas et al., "Prevalence of gastric parietal cell antibodies and intrinsic factor antibodies in primary biliary cirrhosis," Clinica Chimica Acta, vol. 411, no. 5-6, pp. 411-415, 2010.

[42] P. Muratori, L. Muratori, M. Guidi et al., "Anti-Saccharomyces cerevisiae antibodies (ASCA) and autoimmune liver diseases," Clinical and Experimental Immunology, vol. 132, no. 3, pp. 473-476, 2003.

[43] F. W. Miller, K. M. Pollard, C. G. Parks et al., "Criteria for environmentally associated autoimmune diseases," Journal of Autoimmunity. In press.

[44] C. Selmi, P. S. Leung, D. H. Sherr et al., "Mechanisms of environmental influence on human autoimmunity: a national institute of environmental health sciences expert panel workshop," Journal of Autoimmunity. In press.

[45] G. Disanto, G. Chaplin, J. M. Morahan et al., "Month of birth, vitamin D and risk of immune mediated disease: a case control study," BMC Medicine, vol. 10, no. 1, article 69, 2012.

[46] D. S. Smyk, E. I. Rigopoulou, L. Muratori et al., "Smoking as a risk factor for autoimmune liver disease: what we can learn from primary biliary cirrhosis," Annals of Hepatology, vol. 11, no. 1, pp. 7-14, 2012.

[47] F. K. Varyani, J. West, and T. R. Card, "An increased risk of urinary tract infection precedes development of primary biliary cirrhosis," BMC Gastroenterology, vol. 11, article 95, 2011.

[48] M. S. Longhi, Y. Ma, D. P. Bogdanos, P. Cheeseman, G. Mieli-Vergani, and D. Vergani, "Impairment of CD4+CD25+ regulatory T-cells in autoimmune liver disease," Journal of Hepatology, vol. 41, no. 1, pp. 31-37, 2004.

[49] I. Monteleone, F. Pallone, and G. Monteleone, “Th17-related cytokines: new players in the control of chronic intestinal inflammation," BMC Medicine, vol. 9, article 122, 2011.

[50] J. M. Anaya, R. Corena, J. Castiblanco, A. Rojas-Villarraga, and Y. Shoenfeld, "The kaleidoscope of autoimmunity: multiple autoimmune syndromes and familial autoimmunity," Expert Review of Clinical Immunology, vol. 3, no. 4, pp. 623635, 2007.

[51] M. Blank and M. E. Gershwin, "Autoimmunity: from the mosaic to the kaleidoscope," Journal of Autoimmunity, vol. 30, no. 1-2, pp. 1-4, 2008.

[52] I. Dalal, A. Levine, E. Somekh, A. Mizrahi, and A. Hanukoglu, "Chronic urticaria in children: expanding the “autoimmune kaleidoscope",' Pediatrics, vol. 106, no. 5, pp. 1139-1141, 2000.

[53] M. Lorber, M. E. Gershwin, and Y. Shoenfeld, "The coexistence of systemic lupus erythematosus with other autoimmune diseases: the kaleidoscope of autoimmunity," Seminars in Arthritis and Rheumatism, vol. 24, no. 2, pp. 105-113, 1994.
[54] Y. Shoenfeld, “The kaleidoscope of autoimmunity," Autoimmunity, vol. 15, no. 3, pp. 245-252, 1993.

[55] Y. Shoenfeld, M. Lorber, T. Yucel, and H. Yazici, "Primary antiphospholipid syndrome emerging following thymectomy for myasthenia gravis: additional evidence for the kaleidoscope of autoimmunity," Lupus, vol. 6, no. 5, pp. 474-476, 1997.

[56] P. Weiss and Y. Shoenfeld, "Shifts in autoimmune diseases: the kaleidoscope of autoimmunity," Israel Journal of Medical Sciences, vol. 27, no. 4, pp. 215-217, 1991.

[57] M. Fallena Zonana, E. Reyes, and A. K. Weisman, "Coexistence of four autoimmune diseases in one patient: the kaleidoscope of autoimmunity," Journal of Clinical Rheumatology, vol. 8, no. 6, pp. 322-325, 2002.

[58] J. L. Siegel, H. Luthra, J. Donlinger, P. Angulo, and K. Lindor, "Association of primary biliary cirrhosis and rheumatoid arthritis," Journal of Clinical Rheumatology, vol. 9, no. 6, pp. 340-343, 2003.

[59] M. Clark and K. Sack, "Deforming arthropathy complicating primary biliary cirrhosis," Journal of Rheumatology, vol. 18, no. 4, pp. 619-621, 1991.

[60] J. Duffy, "Arthritis and hepatitis," Bulletin on the Rheumatic Diseases, vol. 47, no. 2, pp. 1-5, 1998.

[61] K. Lauritsen and H. Diederichsen, "Arthritis in patients with antimitochondrial antibodies," Scandinavian Journal of Rheumatology, vol. 12, no. 4, pp. 331-335, 1983.

[62] W. J. Marx and D. J. O’Connell, "Arthritis of primary biliary cirrhosis," Archives of Internal Medicine, vol. 139, no. 2, pp. 213-216, 1979.

[63] S. Sherlock and P. J. Scheuer, "The presentation and diagnosis of 100 patients with primary biliary cirrhosis," The New England Journal of Medicine, vol. 289, no. 13, pp. 674-678, 1973.

[64] C. Caramella, J. Avouac, P. Sogni, X. Puéchal, A. Kahan, and Y. Allanore, "Association between rheumatoid arthritis and primary biliary cirrhosis," Joint Bone Spine, vol. 74, no. 3, pp. 279-281, 2007.

[65] K. Inoue, J. Hirohara, T. Makano et al., "Prediction of prognosis of primary biliary cirrhosis in Japan," Liver, vol. 15, no. 2, pp. 70-77, 1995.

[66] B. Marasini, M. Gagetta, V. Rossi, and P. Ferrari, "Rheumatic disorders and primary biliary cirrhosis: an appraisal of 170 Italian patients," Annals of the Rheumatic Diseases, vol. 60, no. 11, pp. 1046-1049, 2001.

[67] C. Selmi, M. De Santis, and M. E. Gershwin, "Liver involvement in subjects with rheumatic disease," Arthritis Research \& Therapy, vol. 13, no. 3, article 226, 2011.

[68] E. M. Ruderiman, J. M. Crawford, A. Maier, J. J. Liu, E. M. Gravallese, and M. E. Weinblatt, "Histologic liver abnormalities in an autopsy series of patients with rheumatoid arthritis," British Journal of Rheumatology, vol. 36, no. 2, pp. 210-213, 1997.

[69] A. Datta, S. D. Deodhar, U. Datta, and S. Sehgal, "Nonorgan specific and organ specific antibodies in rheumatoid arthritis," Indian Journal of Medical Research B, vol. 92, pp. 228-232, 1990.

[70] C. Corpechot, Y. Chrétien, O. Chazouillères, and R. Poupon, "Demographic, lifestyle, medical and familial factors associated with primary biliary cirrhosis," Journal of Hepatology, vol. 53, no. 1, pp. 162-169, 2010.

[71] M. E. Gershwin, C. Selmi, H. J. Worman et al., "Risk factors and comorbidities in primary biliary cirrhosis: a controlled interview-based study of 1032 patients," Hepatology, vol. 42, no. 5, pp. 1194-1202, 2005. 
[72] A. Parikh-Patel, E. B. Gold, H. Worman, K. E. Krivy, and M. E. Gershwin, "Risk factors for primary biliary cirrhosis in a cohort of patients from the United States," Hepatology, vol. 33, no. 1, pp. 16-21, 2001.

[73] M. I. Prince, S. J. Ducker, and O. F. W. James, "Case-control studies of risk factors for primary biliary cirrhosis in two United Kingdom populations," Gut, vol. 59, no. 4, pp. 508512,2010 .

[74] G. M. Hirschfield and P. Invernizzi, "Progress in the genetics of primary biliary cirrhosis," Seminars in Liver Disease, vol. 31, no. 2, pp. 147-156, 2011.

[75] P. Invernizzi, "Human leukocyte antigen in primary biliary cirrhosis: an old story now reviving," Hepatology, vol. 54, no. 2, pp. 714-723, 2011.

[76] P. Invernizzi, M. Ransom, S. Raychaudhuri et al., "Classical HLA-DRB1 and DPB1 alleles account for HLA associations with primary biliary cirrhosis," Genes and Immunity, vol. 13, no. 6, pp. 461-468, 2012.

[77] P. Invernizzi, C. Selmi, F. Poli et al., "Human leukocyte antigen polymorphisms in Italian primary biliary cirrhosis: a multicenter study of 664 patients and 1992 healthy controls," Hepatology, vol. 48, no. 6, pp. 1906-1912, 2008.

[78] G. F. Mells, J. A. B. Floyd, K. I. Morley et al., "Genomewide association study identifies 12 new susceptibility loci for primary biliary cirrhosis," Nature Genetics, vol. 43, no. 4, pp. 329-332, 2011.

[79] C. Selmi, N. J. Torok, A. Affronti, and M. E. Gershwin, "Genomic variants associated with primary biliary cirrhosis," Genome Medicine, vol. 2, no. 1, article 5, 2010.

[80] A. Tanaka, P. Invernizzi, H. Ohira et al., "Replicated association of 17q12-21 with susceptibility of primary biliary cirrhosis in a Japanese cohort," Tissue Antigens, vol. 78, no. 1, pp. 65-68, 2011.

[81] A. Tanaka, H. Ohira, K. Kikuchi et al., "Genetic association of Fc receptor-like 3 polymorphisms with susceptibility to primary biliary cirrhosis: ethnic comparative study in Japanese and Italian patients," Tissue Antigens, vol. 77, no. 3, pp. 239-243, 2011.

[82] P. Danoy, W. Meng, H. Johanna et al., "Association of variants in MMEL1 and CTLA4 with rheumatoid arthritis in the Han Chinese population," Annals of the Rheumatic Diseases, vol. 70, pp. 1793-1797, 2011.

[83] T. Nanki, K. Takada, Y. Komano et al., "Chemokine receptor expression and functional effects of chemokines on B cells: implication in the pathogenesis of rheumatoid arthritis," Arthritis Research and Therapy, vol. 11, no. 5, article R149, 2009.

[84] Y. Okada, C. Terao, K. Ikari et al., "Meta-analysis identifies nine new loci associated with rheumatoid arthritis in the Japanese population," Nature Genetics, vol. 44, no. 5, pp. 511516, 2012.

[85] E. A. Stahl, S. Raychaudhuri, E. F. Remmers et al., "Genomewide association study meta-analysis identifies seven new rheumatoid arthritis risk loci," Nature Genetics, vol. 42, no. 6, pp. 508-514, 2010.

[86] R. F. van Vollenhoven, "Sex differences in rheumatoid arthritis: more than meets the eye," BMC Medicine, vol. 7, article 12, 2009.

[87] E. J. Walker, G. M. Hirschfield, C. Xu et al., "CTLA4/ICOS gene variants and haplotypes are associated with rheumatoid arthritis and primary biliary cirrhosis in the Canadian population," Arthritis and Rheumatism, vol. 60, no. 4, pp. 931-937, 2009.
[88] F. Meda, M. Folci, A. Baccarelli, and C. Selmi, "The epigenetics of autoimmunity," Cellular and Molecular Immunology, vol. 8, no. 3, pp. 226-236, 2011.

[89] Y. Renaudineau, "The revolution of epigenetics in the field of autoimmunity," Clinical Reviews in Allergy and Immunology, vol. 39, no. 1, pp. 1-2, 2010.

[90] M. M. Mitchell, A. Lleo, L. Zammataro et al., "Epigenetic investigation of variably $\mathrm{X}$ chromosome inactivated genes in monozygotic female twins discordant for primary biliary cirrhosis," Epigenetics, vol. 6, no. 1, pp. 95-102, 2011.

[91] C. Ospelt, K. A. Reedquist, S. Gay, and P. P. Tak, "Inflammatory memories: is epigenetics the missing link to persistent stromal cell activation in rheumatoid arthritis?" Autoimmunity Reviews, vol. 10, no. 9, pp. 519-524, 2011.

[92] L. C. Huber, M. Brock, H. Hemmatazad et al., "Histone deacetylase/acetylase activity in total synovial tissue derived from rheumatoid arthritis and osteoarthritis patients," Arthritis and Rheumatism, vol. 56, no. 4, pp. 1087-1093, 2007.

[93] T. Kawabata, K. Nishida, K. Takasugi et al., "Increased activity and expression of histone deacetylase 1 in relation to tumor necrosis factor-alpha in synovial tissue of rheumatoid arthritis," Arthritis Research and Therapy, vol. 12, no. 4, article R133, 2010.

[94] H. S. Lin, C. Y. Hu, H. Y. Chan et al., "Anti-rheumatic activities of histone deacetylase (HDAC) inhibitors in vivo in collagen-induced arthritis in rodents," British Journal of Pharmacology, vol. 150, no. 7, pp. 862-872, 2007.

[95] K. Nishida, T. Komiyama, S. I. Miyazawa et al., "Histone deacetylase inhibitor suppression of autoantibody-mediated arthritis in mice via regulation of p16INK4a and p21 WAF1/Cip1 expression," Arthritis and Rheumatism, vol. 50, no. 10, pp. 3365-3376, 2004.

[96] S. Lefèvre, A. Knedla, C. Tennie et al., "Synovial fibroblasts spread rheumatoid arthritis to unaffected joints," Nature Medicine, vol. 15, no. 12, pp. 1414-1420, 2009.

[97] M. Miozzo, C. Selmi, B. Gentilin et al., "Preferential X chromosome loss but random inactivation characterize primary biliary cirrhosis," Hepatology, vol. 46, no. 2, pp. 456-462, 2007.

[98] G. Chabchoub, E. Uz, A. Maalej et al., "Analysis of skewed Xchromosome inactivation in females with rheumatoid arthritis and autoimmune thyroid diseases," Arthritis Research and Therapy, vol. 11, no. 4, article R106, 2009.

[99] D. P. Bogdanos, H. Baum, D. Vergani, and A. K. Burroughs, "The role of $E$. coli infection in the pathogenesis of primary biliary cirrhosis," Disease Markers, vol. 29, no. 6, pp. 301-311, 2010.

[100] M. M. Newkirk, A. Zbar, M. Baron, and A. R. Manges, "Distinct bacterial colonization patterns of Escherichia coli subtypes associate with rheumatoid factor status in early inflammatory arthritis," Rheumatology, vol. 49, no. 7, pp. 1311-1316, 2010.

[101] V. Pordeus, M. Szyper-Kravitz, R. A. Levy, N. M. Vaz, and Y. Shoenfeld, "Infections and autoimmunity: a panorama," Clinical Reviews in Allergy and Immunology, vol. 34, no. 3, pp. 283-299, 2008.

[102] M. M. Newkirk, R. Goldbach-Mansky, B. W. Senior, J. Klippel, H. R. Schumacher Jr., and H. S. El-Gabalawy, "Elevated levels of IgM and IgA antibodies to Proteus mirabilis and IgM antibodies to Escherichia coli are associated with early rheumatoid factor (RF)-positive rheumatoid arthritis," Rheumatology, vol. 44, no. 11, pp. 1433-1441, 2005. 


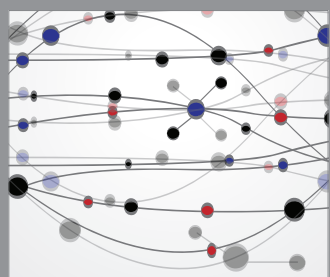

The Scientific World Journal
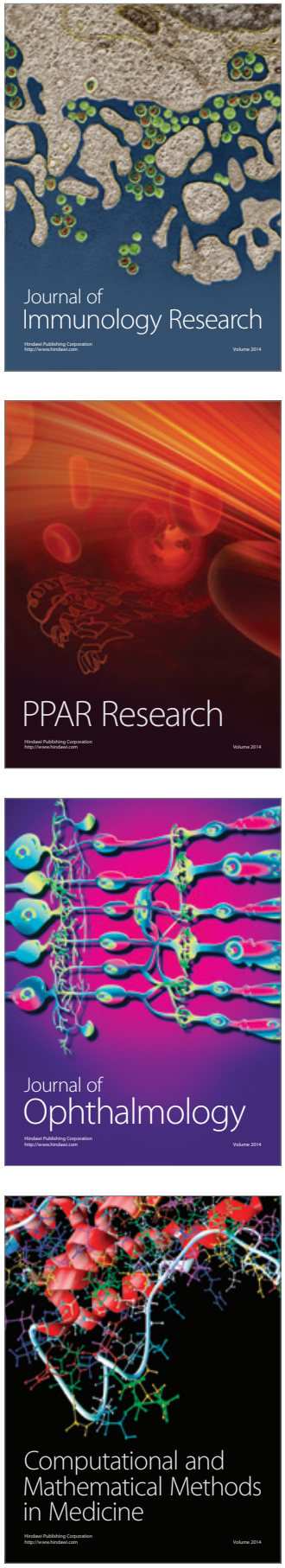

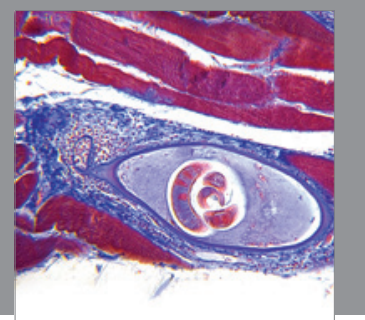

Gastroenterology

Research and Practice
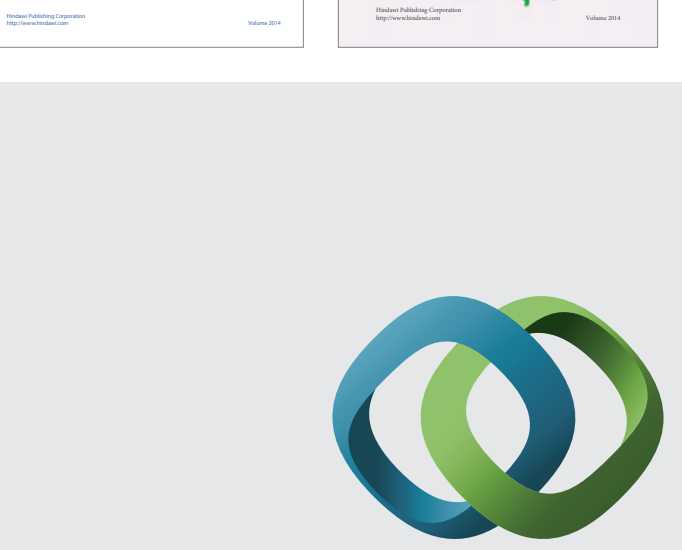

\section{Hindawi}

Submit your manuscripts at

http://www.hindawi.com
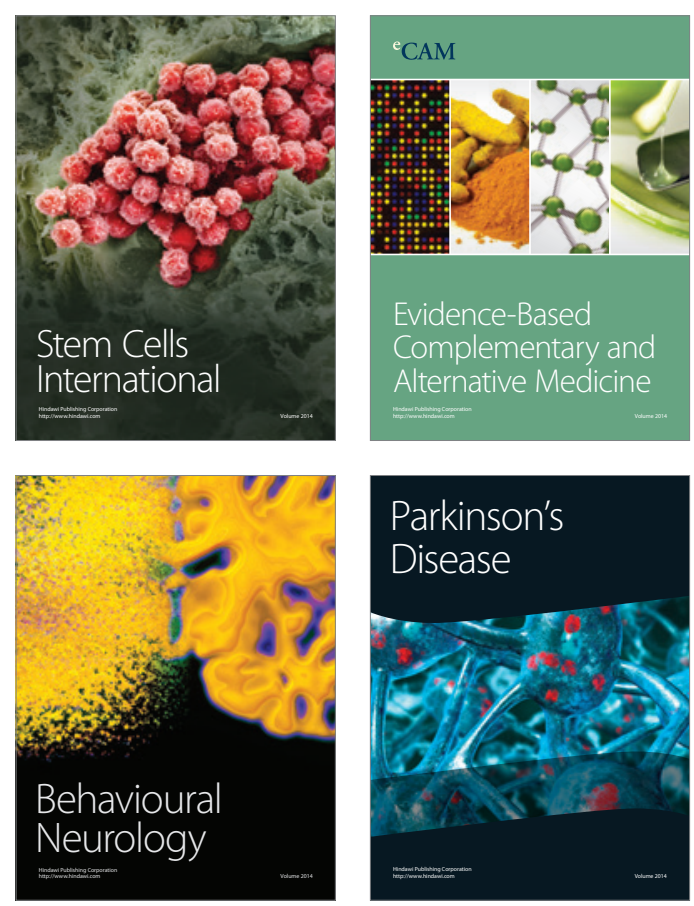

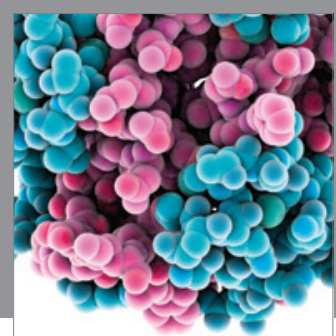

Journal of
Diabetes Research

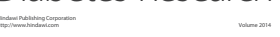

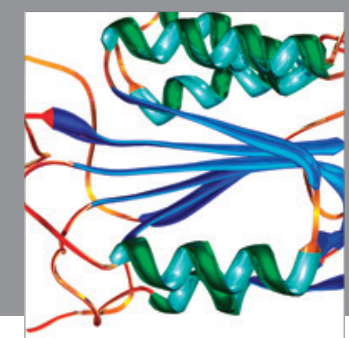

Disease Markers
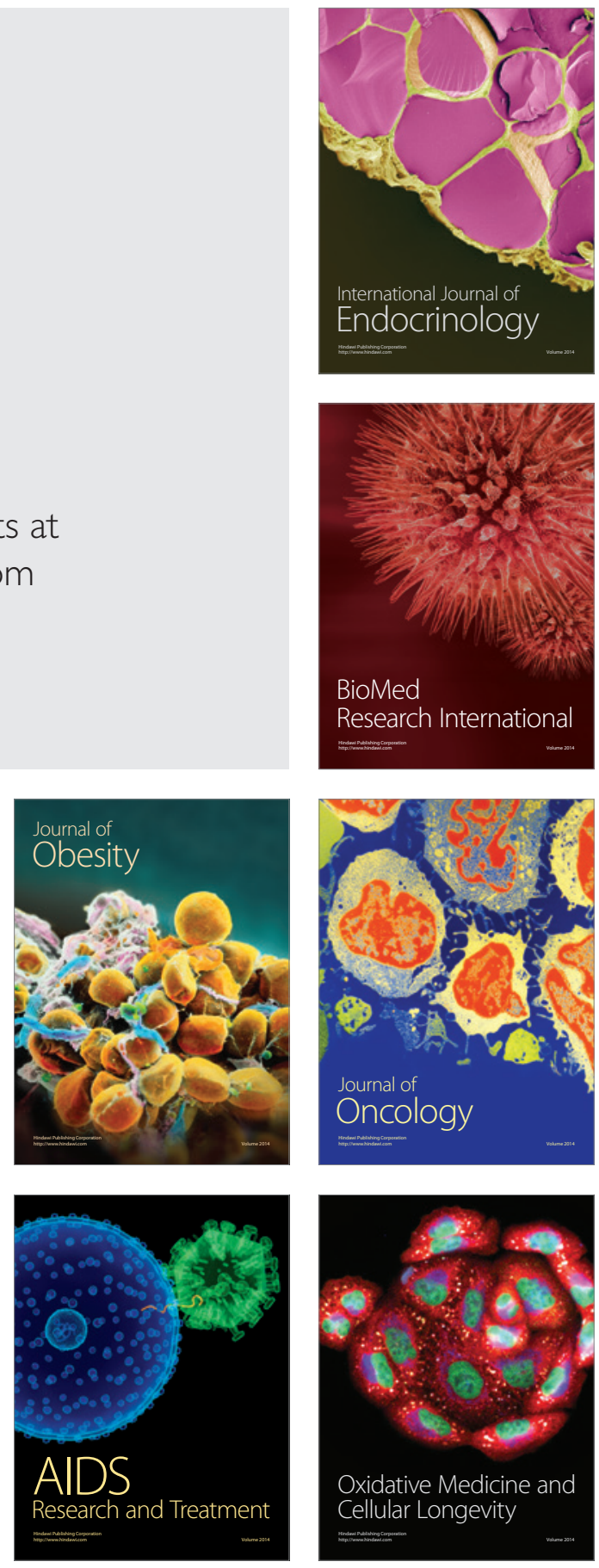